\section{Calcium Intake and Disease Prevention}

\begin{abstract}
While the fundamental metabolic function of calcium is to serve as a second messenger, coupling intracellular responses to extracellular signals, nutritional deficiency of calcium is manifested at a higher level of organization: 1) depletion of the calcium nutrient reserve; 2) inadequate complexation of digestive byproducts; and 3) collateral effects of hormones produced primarily to compensate for low calcium intake. The first mechanism contributes to the osteoporosis problem, the second to kidney stones and colon cancer, and the third to hypertension, preeclampsia, obesity, and insulin resistance, among others. Adequate calcium intakes (1000-1500 mg/d) in adults have been shown in controlled trials to lower the risk of osteoporotic fractures, kidney stones, obesity, and hypertension. The best source of calcium is dairy foods, largely because the disorders concerned depend upon multiple nutrients, not just calcium, and dairy provides a broad array of essential nutrients in addition to calcium, and at low cost. (Arq Bras Endocrinol Metab 2006;50/4:685-693)
\end{abstract}

Keywords: Calcium; Osteoporosis; Fracture; Kidney stones; Colon cancer; Hypertension; Obesity; Insulin resistance

\section{RESUMO}

Ingesta de Cálcio e Prevenção de Doença.

Enquanto a principal função metabólica do cálcio é atuar como um secundo mensageiro, acoplando as respostas intracelulares aos sinais extracelulares, a deficiência nutricional do cálcio é manifestada num nível mais alto de organização: 1) depleção da reserva de cálcio; 2) inadequada formação em complexo digestivo; 3) efeitos colaterais dos hormônios produzidos para compensar a baixa reserva de cálcio. 0 primeiro mecanismo contribui para o surgimento da osteoporose, o secundo para cálculos renais e câncer, e o terceiro hipertensão arterial, preeclampsia, obesidade e resistência insulínica, entre outros. Uma adequada ingesta de cálcio (1000-1500 mg/d) tem mostrado em estudos clínicos controlados em adultos, reduzir os riscos de fraturas osteoporóticas, cálculos renais, obesidade e hipertensão. A melhor fonte de cálcio são os laticínios, porque além do cálcio, fornecem múltiplos nutrientes e são de baixo custo. (Arq Bras Endocrinol Metab 2006;50/4:685-693)

Descritores: Cálcio; Osteoporose; Fratura; Cálculo renal; Câncer colônico; Hipertensão; Obesidade; Resistência insulínica

$\mathbf{T}$ HE HUMAN BODY AT BIRTH typically contains $25-30 \mathrm{~g}$ calcium, and at maturity, $1000-1500 \mathrm{~g}$ calcium. All of this difference must come in by way of the diet. In that trivial sense, calcium is an essential nutrient for growth. But the requirement for calcium remains relatively high even after growth has been completed, largely because absorption efficiency from food calcium sources is poor and excretory conservation is weak. Hence, adequate calcium intake remains important throughout life. review article

Robert P. Heaney

Creighton University, Omaha, NE, USA.
Received in 05/09/06 Accepted in 05/23/06 
Approximately $99 \%$ of total body calcium is located in the bones and teeth, $1 \%$ in the various tissues of the body, and $0.1 \%$ in extracellular water. The principal metabolic function of calcium is to serve as a second messenger coupling various intracellular responses to extracellular signals ( 1 ). The prototypical example is the role that calcium plays in the activation of muscle contraction. Ionized calcium in the cell sap is maintained at extremely low levels (typically 3-4 orders of magnitude lower than in the extracellular fluid bathing the cell). When a cell is stimulated to produce its proper action, calcium enters the cell sap either from the extracellular fluid or from intracellular storage vesicles, activating the various proteins that mediate cell action. Then, virtually immediately, various ion pumps remove the calcium from the cell sap either to the extracellular fluid or to intracellular storage where it awaits another activation cycle. This fundamental mechanism seems to be virtually universal across the animal kingdom and is essential for all cellbased life.

Calcium is unlike most nutrients in that the manifestations of deficiency are largely independent of this fundamental metabolic role in cell activation. Instead, deficiency of calcium is expressed at a higher level of organization by three mechanisms that are quite distinct from its intracellular function:

- The skeleton serves as the calcium nutrient reserve, and at the same time provides support and strength for the mechanical activities of the body; while partial depletion of this reserve will inevitably compromise bone strength, the remaining reserve will always be sufficient to protect the fundamental metabolic function of calcium; thus, not metabolic deficiency, but depletion of the reserve (bone) is what causes disease by this mechanism.

- Because calcium absorption from the gut is poor (averaging $10 \%$ of ingested calcium at prevailing intakes), most food calcium remains in the intestinal lumen, where it is available to bind with potentially harmful byproducts of digestion. With low calcium diets there will usually not be enough unabsorbed calcium in the gut fully to complex these potentially noxious substances.

- The hormonal responses evoked to sustain extracellular fluid calcium ion concentration (ECF $\left.\left[\mathrm{Ca}^{++}\right]\right)$in the face of low calcium intakes exert collateral effects on tissues unrelated to the calcium economy, which, operating through calcium's basic metabolic function, contribute to development or aggravation of a variety of chronic diseases.

\section{SKELETAL EFFECTS}

The importance of an adequate calcium intake for bone health has been abundantly documented and is reflected in a variety of nutritional policy statements, ranging from the Surgeon General's Report on Bone Health and Osteoporosis (2) to various NIH Consensus Conferences (3-6) and the Institute of Medicine's Dietary Reference Intakes for the Bone-Related Nutrients (7). The current recommendations for dietary calcium intake in the United States are $500-800 \mathrm{mg} / \mathrm{d}$ up to age $8,1300 \mathrm{mg} / \mathrm{d}$ up to age $19,1000 \mathrm{mg} / \mathrm{d}$ thereafter up to age 50 , and $1200 \mathrm{mg} / \mathrm{d}$ above age 50 . These recommendations are based solely on a skeletal endpoint (see below) and hence may not be optimal for full protection of the diseases related to the other two mechanisms by which calcium intake exerts an effect.

The primary role of calcium intake in the adult is to offset daily losses through excreta, sweat, and shed skin, nails, and hair. Excretory conservation for calcium is weak and when excretion exceeds absorbed input, the skeleton is torn down to scavenge its calcium. In addition to protecting skeletal mass, high calcium intakes reduce the excessive remodeling common in postmenopausal women and in many osteoporotics (8). High remodeling is a risk factor for fracture that is probably at least as important as low bone mass (9). This is shown, for example, by the fact that remodeling rate predicts fracture (10); and, in treatment trials with either bisphosphonates or calcium and vitamin $\mathrm{D}$, fracture rate falls immediately after starting treatment, before bone mass can have changed appreciably (11).

From a skeletal standpoint, calcium exhibits what is called "threshold" behavior, as depicted in figure 1 (12). What this means is that as calcium intake rises, calcium retention (i.e., bone mass) rises as well, but only up to a certain threshold level. This threshold intake occurs at a positive retention value during growth, at zero retention during the peak adult years, and at a negative retention value during involution. Above that threshold intake no further retention occurs, no matter how high the calcium intake. (This is the same sort of behavior exhibited by iron and circulating hemoglobin mass. In iron deficiency anemia, iron supplementation raises hemoglobin mass, but only up to normal values, above which further iron intake produces no further hemoglobin.) For the current calcium intake recommendations, the average point at which different age groups reached their threshold was taken as the estimated average requirement for the population, a figure that was designated 


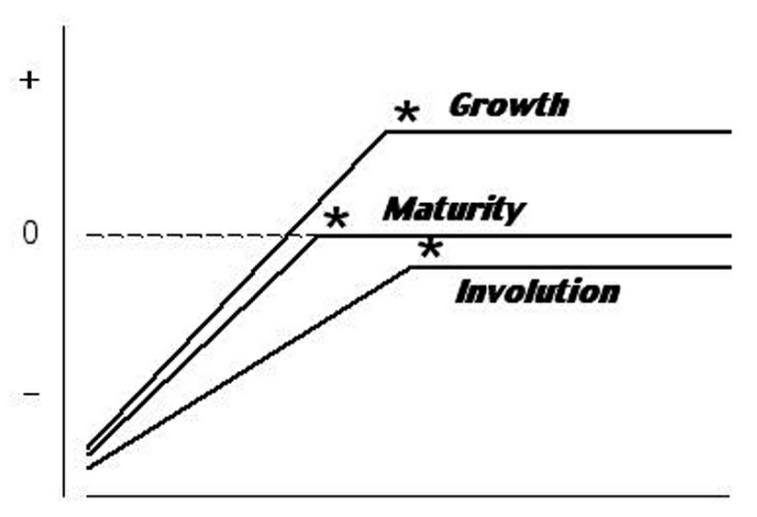

CALCIUM INTAKE

Figure 1. Diagrammatic threshold curves for calcium retention (equivalent to bone mass) as a function of calcium intake, for three principal life stages. The asterisks mark the location of the threshold values for each. (Copyright Robert P. Heaney, 1998. Used with permission.)

"Adequate Intake" (AI) in the final report of the Food and Nutrition Board (FNB) (7). Other disease endpoints were not factored into this analysis, and it is highly likely that the third category of disease, resulting from collateral effects of compensation for low calcium intake, would not be fully optimized until some intake further to the right of the bony retention threshold. (The exact value is not known, which is the reason the FNB focused on a skeletal endpoint, where the evidence is abundant.)

The threshold diagram of figure 1 is useful for explicating a number of features of the calcium economy. One is that the curves differ by ethnic status. Figure 2 illustrates this point, contrasting the curve for African-Americans (A-A) with that for Caucasians and East Asians. The curve for A-A is shifted to the left, indicating both that the A-A utilize dietary calcium more efficiently (the steepness of the ascending limb) and reache the plateau at a lower dietary intake. Available evidence indicates that the reason behind this difference is the fact that the A-A bony resorptive apparatus is relatively resistant to parathyroid hormone (PTH, the master controller of calcium homeostasis) $(13,14)$. Because of this resistance, at the low calcium intakes typical of A-A, both PTH secretion and calcitriol levels are high, and urinary calcium is low (15). Additionally, at some life stages, calcium absorption is higher in A-A than in Caucasians, as well. Together these adjustments allow an A-A to accumulate a skeletal mass (and to maintain it) at a lower calcium intake than would be required by Caucasians and East Asians. However, to do this the A-A must live with chronically high PTH and calcitriol levels (see below "Off-loop

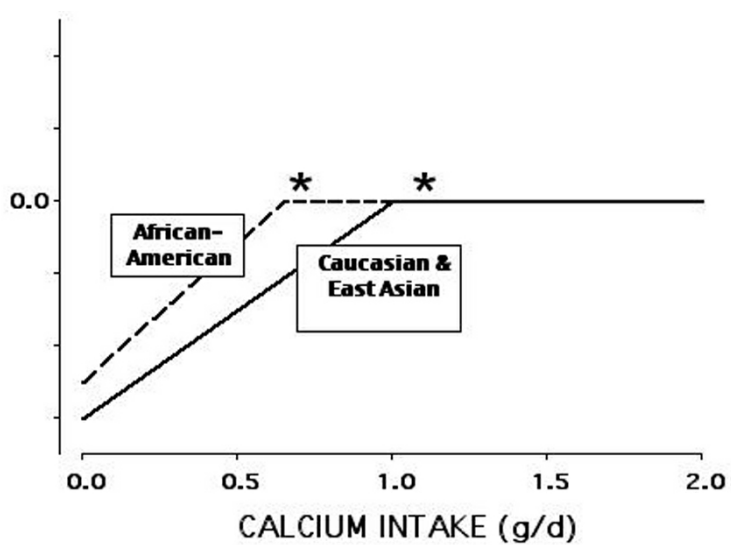

Figure 2. Diagrammatic threshold curves, as in figure 1, contrasting performance in adult African-Americans with that of Caucasians and East Asians. (Copyright Robert P. Heaney, 2001. Used with permission.)

effects"). The size of the difference in the threshold value between the three racial groups is not known with any certainty, but is likely to be on the order of 300-500 mg/d lower for A-A.

The interaction of a number of physiological and pharmacological agents with the calcium economy can also be best understood by reference to this threshold diagram. For example, the loss of estrogen at menopause results in a rightward shift of the curve, so that the ascending limb is less steep (diet calcium is utilized less efficiently), and the threshold intake required to maintain equilibrium is higher. By contrast, bisphosphonate drugs, by antagonizing osteoclastic resorption, create a situation of $\mathrm{PTH}$ resistance analogous to that native to A-A (though the extent of the shift is uncertain). Patients treated with bisphosphonates have reduction in serum calcium, particularly under fasting conditions (e.g., overnight), a reduction in urinary calcium excretion, and an elevation of serum PTH (16).

When one examines the totality of the evidence, it becomes clear that the vast majority of studies evaluating the relationship between calcium intake and either bone mass, age-related bone mass, or fracture show a beneficial effect of high calcium intake. Nevertheless there are a few studies finding no effect (1719). Some negative studies are to be expected whenever investigative power is less than $100 \%$. However, there is one important consideration that, by itself, explains several of the negative studies, and its elucidation is helped once again, by reference to the threshold diagram. Figure 3 contrasts the intakes that must be studied if, in a controlled trial, one is to find a mea- 
surable effect. The low (i.e., control) intake must be far enough down the ascending limb of the curve to allow the calcium supplementation to produce a difference. If, instead, both the control and the treated groups are at or above the threshold, then the effect will be negligible to non-existent, just as would be the case with giving extra iron to someone who was not iron deficient. That is precisely what happened in the recently published calcium arm of the Women's Health Initiative (WHI) (19). Going into study, the WHI participants had mean calcium intakes in excess of $1100 \mathrm{mg} / \mathrm{d}$, or virtually the same as the $1200 \mathrm{mg}$ recommendation from the FNB (7). While the calcium-supplemented group got substantially more calcium, there was little evident fracture risk reduction. Figure 3 shows why this was to have been expected. While one might fault the design of WHI in this regard, it must be admitted that there are difficult ethical problems involved. Given the plethora of public policy statements and the body of the evidence indicating a benefit of an adequate calcium intake, it would have been unethical deliberately to place a control group on a calcium intake that was likely to produce major fractures.

\section{GUT EFFECTS}

\section{Oxalate and kidney stones}

Only a small fraction of the total renal oxalate burden each day comes from absorbed oxalate; nevertheless, variations in that quantity appear to have a significant effect on kidney stone risk. Curhan et al., a number of years ago (20), showed an inverse association between calcium intake and kidney stone risk in the Harvard Health Professions Study, presumably because high calcium intakes reduced the absorption of oxalate. Several years later Borghi et al., in a 5-year randomized, controlled trial in male stone-formers, showed that a high calcium intake from food sources (mainly dairy) reduced stone recurrences by $50 \%$ in comparison to a calcium-restricted diet (21). Furthermore, as proof of concept, they showed that urinary oxalate rose on the calcium-restricted diet, but fell on the high calcium diet. Both of these studies were in men, and the situation in women may be somewhat different. In the Nurses' Health Study, Curhan et al. (22) showed that stone risk was inversely associated with dietary calcium intake, just as for men, but that supplemental calcium intake seemed to have a paradoxical effect, supplemental calcium intakes in the range of $200-500 \mathrm{mg} / \mathrm{d}$ were associated with a higher stone
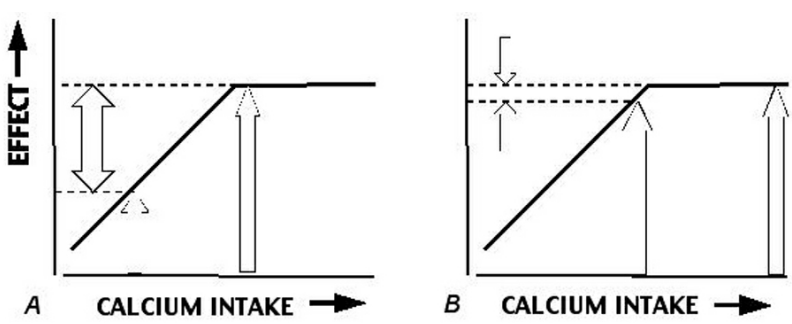

Figure 3. Threshold curves for adults showing diagrammatically why, in studies testing the hypothesis that augmented calcium intakes will improve calcium retention (or its concomitants, bone mass, and bone strength). One of the contrast groups must have an intake below the threshold value. A. The ideal design. B. The design employed in several failed trials, notably WHI (19). (Copyright Robert P. Heaney, 2006. Used with permission.)

risk than supplemental intakes at higher levels. Similarly, in WHI, stone risk was increased in the calcium arm by a factor of 1.17 (19). While this is a small increase in risk for a problem that is relatively uncommon in women in the first place, it was nevertheless statistically significant.

A possible explanation for some of these discrepancies may be found in the fact that both calcium and oxalate are risk factors for kidney stones in stoneprone individuals. When calcium intake goes up, absorbed calcium rises, and hence urinary calcium rises as well. On balance, however, urinary oxalate is a more powerful risk factor for stones than is urinary calcium, and hence the decline in oxalate excretion more than offsets the stone-promoting effect of the rise in urine calcium. But once food oxalate has been fully complexed, then further increases in calcium intake produce no additional lowering of urinary oxalate, while they continue to elevate urine calcium. It may be that, as in WHI, when one compares a $1700 \mathrm{mg}$ intake to an $1100 \mathrm{mg}$ intake, the main effect will be that of the extra urinary calcium excretion. It may also be that calcium carbonate, the commonest chemical form in supplements in North America, has an effect on stone risk, which is different from that of food calcium. (It is likely, at least, that it would have a greater alkalinizing effect than typical food sources.)

\section{Cancer promoters}

Colon cancer has a complex etiology, but there is a persuasive body of evidence (human and animal) indicating that both unabsorbed fatty acids and certain bile acids, through their irritating effect on the mucosa, serve as cancer promoters (23). Both the bile acids and the fatty acids are complexed by calcium and, in effect, rendered innocuous. But it takes a high cal- 
cium diet for there to be sufficient calcium in the digestive residue fully to complex the load of potential irritants.

In one randomized, controlled trial calcium carbonate reduced polyp recurrence in high risk patients by about $25 \%(24)$, and in a number of observational, epidemiological studies, there is a highly significant inverse relationship between cancer risk and calcium intake, particularly when the calcium comes from dairy sources $(23,25,26)$. It has been speculated that part of the dairy effect is due to the fact that calcium phosphate binds taurocholic acid more efficiently than calcium carbonate (25).

The calcium intake that is optimal for colon cancer prevention is not known with any certainty, but it appears to be somewhat higher than the threshold value for skeletal effects, and may be as high as 1800 $\mathrm{mg} / \mathrm{d}$. As noted below ("Off-loop effects"), for individuals of modern body size, such an intake would not be high in comparison with the hunter-gatherer diet, and so, while unusual today, should not be considered unphysiological.

\section{OFF-LOOP EFFECTS}

Because both absorption and conservation of calcium are poor, the constancy of ECF $\left[\mathrm{Ca}^{++}\right]$depends upon an exquisitely sensitive endocrine control system that adjusts the renal calcium excretory threshold; regulates osteoclastic release of calcium in the process of bone resorption; and alters intestinal calcium absorption by regulating the synthesis of calcitriol in the kidney. All of these actions are mediated by PTH, the secretion of which is highly sensitive to tiny perturbations in ECF $\left[\mathrm{Ca}^{++}\right]$. High primate diets have a calcium density of up to $300 \mathrm{mg} / 100 \mathrm{kcal}$, whereas typical adult diets of contemporary humans exhibit densities closer to 40 $\mathrm{mg} / 100 \mathrm{kcal}$. To the extent that our hunter-gatherer ancestors were like the high primates, their high dietary calcium density would have ensured transfer of large quantities of calcium into the ECF from the gut each day, spread over large fractions of the 24-hr period. By contrast, contemporary diets provide relative smaller calcium inputs over shorter time intervals each day. The PTH mechanism for maintaining ECF $\left[\mathrm{Ca}^{++}\right]$ under primitive circumstances would have been deployed relatively less frequently or less vigorously, and would have heralded relative food shortage. By contrast, energy and calcium intakes in contemporary diets are dissociated from one another, and average 24-hr serum PTH concentrations are high. This is a situation for which human physiology has had no evolutionary experience.

One of the consequences of chronically high PTH levels is a high circulating level of calcitriol. Long recognized as the "active hormonal form" of vitamin D, calcitriol acts on the intestinal mucosa to increase calcium extraction from ingested food. This is an "on-loop" effect, since the evoked increase in calcium absorption down-regulates the signal for calcitriol synthesis. But calcitriol also acts on a number of other tissues that have nothing to do with the calcium economy. One of the effects of such action is an increased sensitivity to, or aggravation of, various chronic diseases, including hypertension, obesity, premenstrual syndrome, the insulin-resistance syndrome, as well as a number of others. In brief, this third mechanism by which calcium deficiency expresses itself is a collateral consequence of the body's attempt to get by on a low calcium intake.

These effects are termed "off-loop" because they are not a part of the negative feedback loop which regulates calcium homeostasis, i.e., they do not feed back on the PTH signal controlling calcitriol synthesis. The precise mechanism for these off-loop effects is doubtless complex, and is not fully understood. One mechanism that has been elucidated is the binding of calcitriol to cell membrane receptors adjacent to calcium channels, with the consequent opening of those channels and the entry of calcium ions into the cell sap (27). This has been shown, for example, in adipocytes and smooth muscle cells. The consequence, for adipocytes, is upregulation of fat synthesis and a down regulation of lipolysis; and for smooth muscle cells in artery walls, increased arteriolar tone and blood pressure. Because of the redundancy of the systems controlling intracellular calcium ion concentration, many individuals will be able to pump the calcium ions out without experiencing an effect of the inappropriate $\mathrm{Ca}^{++}$influx. But individuals with less capacity to do so will, as a result, be more prone to disorders such as hypertension, preeclampsia, the insulin resistance syndrome (IRS), etc. This is almost certainly a large part of the explanation for the increased risk of hypertension and stroke in A-A. As noted above, A-A typically have higher calcitriol levels than Caucasians.

The overall effect of calcium intake in these disorders is exemplified in the CARDIA study (28), which monitored the transition from health to disease in a cohort of young men and women. The transition from overweight to obesity during the 10 years of observation was over $40 \%$ more likely to occur in individuals with the lowest dairy calcium intake; and the transition from normal blood pressure to hypertension in overweight indi- 
viduals, 2.7-fold greater. Further, there was a smooth decrease in risk as dairy intake rose. The authors note that all of the components of IRS were reduced in those with higher calcium intakes, and that each dairy serving per day reduced the development of IRS by $21 \%$.

More direct, experimental evidence comes from the DASH (Dietary Approaches to Stop Hypertension) study (29). In the original DASH experiment a diet rich in fruits and vegetables produced a significant lowering of blood pressure relative to a standard North American diet, particularly in A-A and in individuals with mild hypertension. The addition of dairy products to this fruit and vegetable-rich diet produced a substantially greater reduction in blood pressure, matching that of standard anti-hypertensive pharmacotherapy. In the original DASH experiment sodium intake was held constant across all three diets, and in a subsequent experiment, the effect of three levels of sodium intake were separately assessed (30). While reduced sodium intake lowered blood pressure significantly in the subjects receiving the control diet, on the full DASH diet (fruits, vegetables, dairy) the effect of salt reduction was much smaller and, even without salt restriction, blood pressure was reduced fully as much by the DASH diet as by the most severe of the sodium-restriction regimens for the control diet. Figure 4 shows these contrasts graphically. It is worth recalling in this regard, that the saltsensitive hypertensive rat model requires a low calcium intake for its expression in the test animal. It seems that, in humans as well, salt sensitivity is exaggerated in individuals with lower calcium intakes (31).

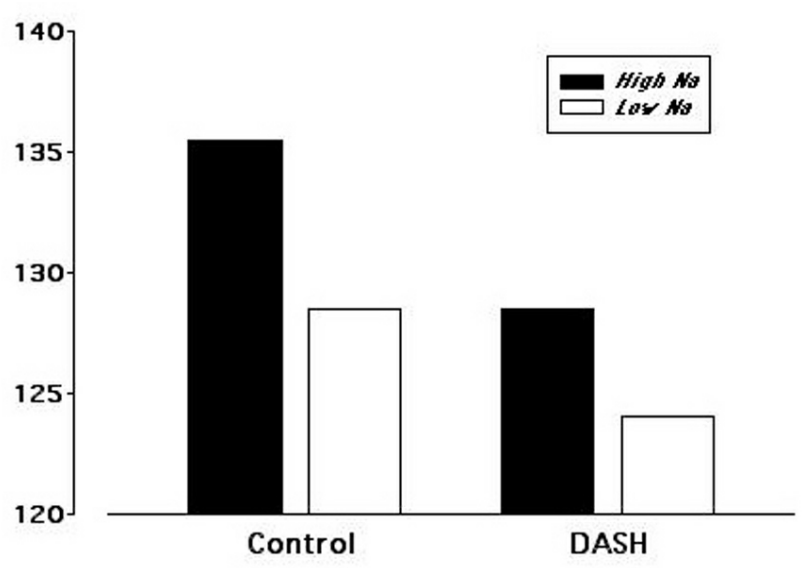

Figure 4. Plot of the data from the DASH-Sodium project (30). The high and low sodium diets contained 3300 and $1500 \mathrm{mg} \mathrm{Na} / \mathrm{d}$, respectively. As is evident, the DASH diet without salt restriction produced as much lowering of blood pressure as did severe salt restriction on the control diet. (Copyright Robert P. Heaney, 2006. Used with permission.)
Several population-based epidemiological studies show an inverse association between calcium intake and risk of obesity, body mass index, or percent body fat (32-34). Additionally, some (but not all) randomized controlled trials of high calcium intakes have shown enhanced weight loss and preservation of lean body mass under conditions of energy restriction $(35,36)$. The precise mechanism is unclear, though some portion may be due to complexation of fatty acids in the gut, preventing their absorption and thereby reducing energy intake. Additionally, food calcium sources (e.g., milk, cheese) have a relatively high satiety value, perhaps aiding adherence to a weight loss regimen. As noted above, the high calcitriol levels characteristic of low calcium intakes shift metabolism of fat cells toward fat storage rather than fat breakdown (27), but this by itself is not sufficient to explain the energy imbalance that is fundamental to weight gain or weight loss.

At a population level the effect of calcium intake is small, explaining $\sim 3 \%$ of the variation in adult body weight. Nevertheless, because the relationship between calcium and body weight is inverse, raising calcium intake in the population at large would be predicted to reduce both mean weight and mean weight gain with age (37) and could thereby substantially reduce the prevalence of obesity.

Presumably operating in a similar way, high calcium intakes have been shown to reduce the symptoms of premenstrual syndrome and to reverse the polycystic ovary syndrome $(38,39)$.

\section{COMMENT}

It is important to stress both that all the diseases discussed are multifactorial in character, and that individuals vary widely in their sensitivity to low calcium intakes. Even osteoporosis, which had, until recently, been defined by a reduction in bone mass, is now recognized to have other important fragility components (summarized in the term "microarchitectural deterioration of bone tissue"). Also, as I have noted, both ethnic and hormonal factors alter the sensitivity of the skeleton to suboptimal calcium intake. The same is true for such disorders as hypertension, obesity, and the insulin resistance syndrome, as well as for colon cancer and kidney stones. A high calcium intake, for example, will not offset the tendency to gain weight if one is consuming more energy than one is expending. On the other hand, if one is attempting to control weight, then a high calcium diet helps, and particular- 
ly a high dairy diet, inasmuch as the high content of branched chain amino acids in dairy protein helps conserve lean body mass, shifting the weight loss to the fat compartment.

So the question is not: "Does a high calcium intake produce beneficial effects in everyone, or completely prevent their developing diseases such as osteoporosis, hypertension, and IRS?" Rather: "Does the disease burden for these disorders at a population level go down as population level calcium intake goes up?" The answer to that second question is clearly "yes". Moreover, raising calcium intake from dietary sources (e.g., dairy) has a highly favorable cost benefit ratio. In fact, the cost of elevating calcium intake in this way at a population level is actually negative. This is partly because calcium-rich foods tend to cost less than alternative foods, and because the benefit produced by elevating calcium intake is not confined to a single body system or disorder.

\section{SOURCES}

Foods are far and away the best sources of the calcium needed to optimize health. The body systems concerned (e.g., bone, the vasculature, etc.) are dependent upon multiple nutrients, and not simply upon calcium; and calcium-rich foods provide a broad array of other nutrients. Protein intake, vitamin D status, potassium intake, etc. have all been shown either in controlled trials or in observational studies to be associated with improved bone status (40-42), and vitamin D and potassium intake reduce the risk and/or severity of hypertension (31). This is one of the reasons why food sources are much to be preferred over mononutrient supplements. The reduction in blood pressure in the DASH diet, using dairy as the source of calcium, was approximately twice as great as had been previously found for calcium carbonate supplements (31), and in several obesity trials, the reduction in body weight, and the conservation of lean body mass using dairy sources of calcium have been shown to be substantially greater than that produced by calcium supplements alone. The possibility that calcium supplements may not have the same stone protective effect as food sources of calcium, noted earlier, may be a similar instance for yet another disease outcome.

Nevertheless, there may be some circumstances in which calcium supplements will be necessary. For the most part, well-formulated supplements will exhibit equal bioavailability, whether they are based on cal- cium carbonate, calcium citrate, or calcium phosphate. However, pharmaceutical formulation of one and the same salt can produce substantial variability in absorbability. Unfortunately, most national registries regulating supplements do not require a demonstration of bioavailability. Hence the best recommendation one can make, after stressing the importance of getting most or all of one's calcium from food sources, is to rely on brand name supplements that have demonstrated their efficacy either in formal studies of bioavailability or in efficacy trials.

Of perhaps greater concern, at least in the context of osteoporosis, is the fact that, with the advent of potent bone active agents, the importance of calcium (and vitamin D) appears to have been lost sight of by both physicians and patients. Calcium is absolutely fundamental to the management of osteoporosis, inasmuch as one makes bone out of mineral, not out of drugs. All of the pharmacologic agents approved for the treatment of osteoporosis were tested only in the context of supplemental calcium intake, and there is no evidence to indicate what their effectiveness might be in the absence of augmented calcium intake. Nevertheless, as Stafford et al. (43) have noted, while physician encounters with respect to osteoporosis have increased dramatically since the introduction of alendronate in the United States in 1995, recommendations concerning calcium intake have fallen by nearly $50 \%$, so that fewer than one in four such encounters include any mention of calcium. Corroboration of that statistic is provided by household consumption data (44) that show that $73 \%$ of the households in which a bisphosphonate is being used are not purchasing enough calcium supplement products to ensure that at least one tablet would be consumed per day per household. Many patients, lacking even a rudimentary understanding of biology, do not realize the importance of maintaining an adequate calcium intake, and unless physicians stress their doing so, it is unlikely that the potential benefit of augmented calcium intake will soon be realized at a population level, even in patients with outspoken disease for which calcium is known to provide a benefit.

\section{REFERENCES}

1. Awumey EM, Bukoski RD. Cellular functions and fluxes of calcium. In: Weaver CM, Heaney RP, eds. Calcium in Human Health. New Jersey: Humana Press, 2006. pp. 1335.

2. Bone Health and Osteoporosis: A Report of the Surgeon General. DHHS (PHS), 2004. 
3. Consensus Development Conference: Prophylaxis and treatment of osteoporosis. Am J Med 1991;90:107-10.

4. Consensus Development Conference: Diagnosis, prophylaxis, and treatment of osteoporosis. Am J Med 1993:94:646-50.

5. Consensus Conference on Optimal Calcium Intake. J Am Med Assoc 1994;272:1942-8.

6. NIH Consensus Statement on Osteoporosis Prevention, Diagnosis and Therapy. vol. 17, Number 1, March 2000. Available at <http:/www.consensus.nih.gov/111/111/ statement.pdf $>$.

7. Food and Nutrition Board, Institute of Medicine. Dietary Reference Intakes for Calcium, Magnesium, Phosphorus, Vitamin D, and Fluoride. Washington: National Academy Press, 1997.

8. Recker RR, Lappe JM, Davies KM, Heaney RP. Bone remodeling increases substantially in the years after menopause and remains increased in older osteoporosis patients. J Bone Miner Res 2004; 19:1628-33.

9. Heaney RP. Is the paradigm shifting? Bone 2003:33:457-65.

10. Eastell R, Barton I, Hannon RA, Chines A, Garnero P, Delmas PD. Relationship of early changes in bone resorption to the reduction in fracture risk with risedronate. J Bone Miner Res 2003; 18:1051-6.

11. Heaney RP, Weaver CM. Newer perspectives on calcium nutrition and bone quality. J Am Coll Nutr 2005;24:574S-81 .

12. Heaney RP. Bone as the calcium nutrient reserve. In: Weaver CM, Heaney RP, eds. Calcium in Human Health. New Jersey: Humana Press, 2006. pp. 7-12.

13. Aloia JF, Mikhail M, Pagan CD, Arunacha-Lam A, Yeh JK, Flaster E. Biochemical and hormonal variables in black and white women matched for age and weight. J Lab Clin Med 1998; 132:383-9.

14. Cosman F, Morgan DC, Nieves JW, Shen V, Luckey MM, Dempster DW, et al. Resistance to bone resorbing effects of PTH in black women. J Bone Miner Res $1997 ; 12: 958-66$.

15. Heaney RP. Ethnicity, bone status, and the calcium requirement. Nutr Res 2002;22:153-78.

16. Greenspan SL, Holland S, Maitland-Ramsey L, Poku M, Freeman $A$, Yuan $W$, et al. Alendronate stimulation of nocturnal parathyroid hormone secretion: a mechanism to explain the continued improvement in bone mineral density accompanying alendronate therapy. Proc Assoc Am Phys 1996; 108:230-8.

17. Grant AM; for the Writing Group. Oral vitamin D3 and calcium for secondary prevention of low-trauma fractures in elderly people (Randomised Evaluation of Calcium or vitamin D, RECORD): a randomized placebo-controlled trial. Lancet 2005;365:1621-8.

18. Porthouse J, Cockayne S, King C, Saxon L, Steele E, Aspray $\mathrm{T}$, et al. Randomised controlled trial of supplementation with calcium and cholecalciferol (vitamin D3) for prevention of fractures in primary care. Br Med J 2005;330:1003-5.

19. Jackson RD, LaCroix AZ, Gass M, Wallace RB, Robbins J, Lewis $C E$, et al. Calcium plus vitamin D supplementation and the risk of fractures. N Engl J Med 2006;354:669-83.
20. Curhan GC, Willett WC, Rimm EB, Stampfer MJ. A prospective study of dietary calcium and other nutrients and the risk of symptomatic kidney stones. $\mathbf{N}$ Engl J Med 1993; 328:833-8.

21. Borghi L, Schianchi T, Meschi T, Guerra A, Allegri F, Maggiore $\mathrm{U}$, et al. Comparison of two diets for the prevention of recurrent stones in idiopathic hypercalciuria. N Engl J Med 2002;346:77-84.

22. Curhan GC, Willett WC, Speizer FE, Spiegelman D, Stampfer MJ. Comparison of dietary calcium with supplemental calcium and other nutrients as factors affecting the risk for kidney stones in women. Ann Intern Med 1997; 126:497-504.

23. Holt PR. Calcium, vitamin D, and cancer. In: Weaver CM, Heaney RP, eds. Calcium in Human Health. New Jersey: Humana Press, 2006. pp. 387-400.

24. Baron JA, Beach M, Mandel JS, van Stolk RU, Haile RW, Rothstein $\mathrm{R}$, et al. Calcium supplements for the prevention of colorectal adenomas. N Engl J Med 1999:340:101-7.

25. Lupton JR. Dairy products and colon cancer: mechanisms of the protective effect. Am J Clin Nutr 1997:66:1065-6.

26. Larsson SC, Bergkvist L, Rutegard J, Giovannucci E, Wolk A. Calcium and dairy food intakes are inversely associated with colorectal cancer risk in the Cohort of Swedish men. Am J Clin Nutr 2006:83:667-73.

27. Shi $H$, Norman AW, Okamura WH, Sen A, Zemel MB. 1 $\alpha, 25$-dihydroxyvitamin D3 modulates human adipocyte metabolism via nongenomic action. FASEB J 2001;15:2751-3.

28. Pereira MA, Jacobs DR, Van Horn L, Slattery ML, Kartashov Al, Ludwig DS. Dairy consumption, obesity, and the insulin resistance syndrome in young adults. J Am Med Assoc 2002;287:2081-9.

29. Appel LJ, Moore TJ, Obarzanek E, Vollmer WM, Svetkey $L P$, Sacks FM, et al. A clinical trial of the effects of dietary patterns on blood pressure. N Engl J Med 1997; 336:1117-24

30. Sacks FM, Svetkey LP, Vollmer WM, Appel LJ, Bray GA, Harsha D, et al. Effects on blood pressure of reduced dietary sodium and the dietary approaches to stop hypertension (DASH) diet. N Engl J Med 2001;344:310.

31. McCarron DA. Hypertension and cardiovascular disease. In: Weaver CM, Heaney RP, eds. Calcium in Human Health. New Jersey: Humana Press, 2006. pp. 421-9.

32. Zemel MB, Shi H, Greer B, DiRienzo D, Zemel PC. Regulation of adiposity by dietary calcium. FASEB J 2000; 14:1132-8.

33. Albertson AM, Good CK, Holschuh NM, Eldridge AL. The relationship between dietary calcium intake and body mass index in adult women: data from the continuing survey of food intake by individuals. FASEB J 2003; 19946. (Abstract \#185.8).

34. Jacamain M, Doucet E, Despres J-P, Bouchard C, Tremblay A. Calcium intake, body composition, and lipoprotein-lipid concentrations in adults. Am J Clin Nutr 2003;77:1448-52. 
35. Zemel MB, Thompson W, Milstead A, Morris K, Campbell P. Calcium and dairy acceleration of weight and fat loss during energy restriction in obese adults. Obes Res 2004; 12:582-90.

36. Zemel MB, Richard J, Mathis S, Milstead A, Gebhardt L, Silva $E$. Dairy augmentation of total and central fat loss in obese subjects. Int J Obesity 2005;29:391-7.

37. Heaney RP. Normalizing calcium intake: projected population effects on body weight. J Nutr 2003; 133:268S-70.

38. Thys-Jacobs J. Premenstrual syndrome. In: Weaver CM, Heaney RP, eds. Calcium in Human Health. New Jersey: Humana Press, 2006. pp. 357-69.

39. Thys-Jacobs S. Polycystic ovary syndrome and reproduction. In: Weaver CM, Heaney RP, eds. Calcium in Human Health. New Jersey: Humana Press, 2006. pp. 341-55.

40. Hannan MT, Tucker KL, Dawson-Hughes B, Cupples LA Felson DT, Kiel DP. Effect of dietary protein on bone loss in elderly men and women: The Framingham Osteoporosis Study. J Bone Miner Res 2000; 15:2504-12.

41. Bischoff-Ferrari HA, Dietrich EJ, Orav B, Dawson-Hughes B. Positive association between 25-hydroxy vitamin D levels and bone mineral density: a population-based study of younger and older adults. Am J Med 2004; 116:634-9.
42. Sebastian A, Harris ST, Ottaway JH, Todd KM, Morris RC Jr. Improved mineral balance and skeletal metabolism in postmenopausal women treated with potassium bicarbonate. N Engl J Med 1994;330:1776-81

43. Stafford RS, Drieling RL, Hersh AL. National trends in osteoporosis visits and osteoporosis treatment, 19882003. Arch Intern Med 2004; 164:1525-30.

44. Procter \& Gamble data, on file.

\section{Address for correspondence:}

Robert P. Heaney

Creighton University Medical Center

601 North $30^{\text {th }}$ Street - Suite 4841

Omaha NE 68131

Fax (402) 280-475

E-mail: rheaney@creighton.edu 